\title{
O devir-corpo dos personagens de David Cronenberg
}

\author{
The becoming-body of David Cronenberg's characters
}

\section{Rosângela Fachel de Medeiros}

Doutora em Literatura Comparada pela Universidade Federal do Rio Grande do Sul. Professora do Mestrado em Letras Literatura Comparada da Universidade Regional Integrada do Alto Uruguai e das Missões (URI).

<rosangelafachel@gmail.com>

\section{RESUMO}

Este artigo analisa a maneira extrema e visceral como o cineasta canadense David Cronenberg apresenta e investiga o corpo humano e a sexualidade em seus filmes, e quais as questões sociais, culturais e artísticas implicadas nessa representação enquanto evidencia das potencialidades transformação do corpo decorrentes dos adventos biotecnológicos e da interação com outros corpos através da violência ou do sexo. Os conceitos de grotesco, formulado por Mikhail Bakhtin, e de abjeção, articulado por Julia Kristeva, permeiam e fundamentam a investigação, auxiliando na compreensão do processo de configuração do devir-corpo cronenberguiano. Nesse sentido, utilizase a ideia de devir, proposta por Gilles Deleuze, como aporte para a compreensão da constante transformação desses corpos em todas as suas vertentes de devir-corpo: devir-animal, devir-monstro e devir-máquina.

\section{ABSTRACT}

This paper examines the extreme and visceral way as the Canadian filmmaker David Cronenberg presents and investigates, in his films, the human body and the sexuality, and what social, cultural and artistic issues involved in this representation as evidence of the potential transformation of the body resulting from biotech advents and interaction with other bodies through violence or sex. The concepts of the grotesque, by Mikhail Bakhtin, and of the abjection, by Julia Kristeva, permeate and underpin this research, aiding the understanding of the configuration process of cronenbergian becoming-body. In this sense, it uses the idea of becoming, proposed by Gilles Deleuze, as contribution to the understanding of the constant transformation of these bodies into all aspects of becoming-body: becoming-animal, becomingmonster and becoming-machine.

Keywords: David Cronenberg. Cinema. Sexuality.

Desde o início de sua carreira, a obra do cineasta canadense David Cronenberg tem gerado controvérsia e fascínio pela maneira extrema como apresenta o corpo humano. Para Shaviro, "os filmes de David Cronenberg centram-se insistente e obsessivamente no corpo, articulando incansavelmente uma política, uma tecnologia, e uma estética da carne" (1993, p. 126, tradução da

1 Colaborou com o levantamento de dados Dhione Oliveira Santana, aluno especial do PPG de Comunicação e Sociedade da Universidade Federal de Sergipe. 
autora). ${ }^{2}$ A investigação das possibilidades de transformação do corpo humano é a marca mais emblemática do cineasta, sendo frequentemente apontada como viga mestra de sua obra. A respeito desse fascínio pelo corpo, declarou o cineasta: "Eu acredito que o corpo humano é o primeiro fato da existência humana. E, para mim, tudo deriva disso: filosofia, religião. Tudo deriva do corpo e da certeza da mortalidade humana. É natural que os meus filmes se foquem nisso" (Cronenberg, 2006, p. 39, tradução da autora) ${ }^{3}$.

Em seus filmes, Cronenberg apresenta a imagem de um corpo em constante transformação, que se desvela em várias configurações: o corpo híbrido: homem-inseto apresentado em $A$ mosca; homem-tecnologia/máquina, em Videodrome, Crash: estranhos prazeres e, também, em A mosca; e homemtecnologia/virtual, em eXistenZ; o corpo protético: em Videodrome, Crash e eXistenZ; o corpo mutante: em Enraivecida na fúria do sexo, Filhos do medo e Gêmeos: mórbida semelhança; o corpo eviscerado: em Scanners, Videodrome e Marcas da violência; e o corpo abjeto e grotesco: em Calafrios, A mosca, Videodrome, Mistérios e paixões, Marcas da violência e Senhores do crime. Além disso, Cronenberg questiona o dualismo mente-corpo em Scanners, A hora da zona morta e em Spider. E torna difusos os limites de gênero homem-mulher no próprio corpo em $M$. Butterfly e em Mistérios e paixões, evidenciando as possibilidades contemporâneas do corpo em relação aos adventos da ciência e da tecnologia, aos seus potenciais de transformação e à interação com outros corpos através da violência ou do sexo.

Ao colocar o corpo e suas vísceras no centro da narrativa, Cronenberg confronta a representação clássica do corpo enquanto unidade fechada, acabada, delimitada e mostrada do exterior, apresentando um corpo grotesco e abjeto.

Bakhtin (1999) define o corpo grotesco como um corpo aberto, irregular, protuberante que é, ao mesmo tempo, múltiplo e mutável, que está em processo contínuo, um corpo sem começo nem fim, um corpo em movimento que jamais está pronto nem acabado: está sempre em estado de construção, de criação; além disso, esse corpo absorve o mundo e é absorvido por ele. Desta forma, enquanto o corpo clássico é fechado, liso e está contido em si mesmo, o corpo grotesco é um corpo aberto, que se projeta. Ignorando a superfície sem falha que

2 Tradução livre de: "David Cronenberg's films focus insistently, obsessively, on the body. They relentlessly articulate a politics, a technology, and an aesthetics of the flesh".

3 Tradução livre de: "I think that the human body is the first fact of the human existence. And for me everything comes out of that: philosophy, religion. Everything comes out of the body and the fact of human mortality. It's natural that my film would focus on that". 
fecha e limita o corpo, o corpo grotesco mostra seu interior: sangue, entranhas, coração e outros órgãos. $E$, muitas vezes, o interior e o exterior fundem-se numa única imagem, revelando a permeabilidade dos limites do corpo em relação ao que entra (comida, bebida) e ao que sai (humores, dejetos, esperma, sangue), bem como quanto aos seus orifícios (boca, ânus, vagina), espaços de transição entre o dentro e o fora.

Essas representações corporais e de partes seccionadas do corpo, bem como de seus fluídos e dejetos geram abjeção. Pois, como nos explica Kristeva (1980), a primeira experiência do ser humano em relação ao mundo é seu contato com o corpo materno que se estabelece através da plenitude, como se houvesse uma conjunção total com o ambiente que o rodeia, sem fronteira alguma. A abjeção serve então, no desenvolvimento humano, para estabelecer os necessários limites entre o indivíduo, os outros e o mundo; impulsionando o indivíduo a tentar se livrar e rejeitar o que não fazer parte dele mesmo: comida, excrementos, urina, vômito, fluidos corporais. A resposta do indivíduo à sensação de abjeção acontece no corpo que se protege com uma reação de repulsa física através de espasmos e vômitos em uma tentativa de se diferenciar e distanciar dessa presença repulsiva. O abjeto não decorre da falta de higiene ou de saúde, mas é aquilo que perturba o sistema, a identidade, a ordem; é aquilo que não respeita as fronteiras, as posições ou as regras, estando no entre, no ambíguo. A repulsa e o horror às imagens abjetas resultam da ambiguidade, da dificuldade de saber se o outro é externo ou se é interno e, por conseguinte, de saber se o outro faz parte do eu. Pois o ser humano se define em oposição ao corpo repulsivo que lhe desagrada, e é esta área de deslize entre o eu e esse outro corpo que ameaça lhe desumanizar, pois está muito próxima a ele.

As imagens grotescas e abjetas dos filmes de Cronenberg, relacionadas à violação do corpo eà exposição de seu interior, de seus humores e dejetos, geram repulsa e desconforto ao exibirem elementos que deveriam estar encerrados no interior do corpo. Em Calafrios os parasitas que infectam os personagens têm um formato semelhante ao de fezes humanas e entram e saem dos corpos dos personagens por seus orifícios. Em Marcas da violência, Scanners e Videodrome cabeças são explodidas e sangue e massa encefálica são espargidos, e o sangue verte voluptuoso nos degolamentos de M. Butterfly e de Senhores do crime. Mas, para o cineasta, essas imagens

não são nojentas. São fascinantes, mas é, também, uma vontade de olhar para o que está realmente lá, sem vacilar, e dizer que é disso que somos feitos, por mais estranho e repugnante que possa parecer, às vezes. $O$ que eu estou dizendo é que o interior do corpo responde 
a uma estética completamente diferente. Eu poderia conceber um concurso de beleza para o interior do corpo humano (Cronenberg citado por Smith, 2000, p. 69, tradução da autora). ${ }^{4}$

O fascínio cronenberguiano pelo interior do corpo se personifica na obsessão dos irmãos Mantle, de Gêmeos: mórbida semelhança, pela beleza interna e visceral do corpo feminino. Cronenberg leva o corpo ao extremo, colocando-o no limiar entre o prazer e o horror e por vezes rompendo esse limite. Conforme William Beard, "os filmes de Cronenberg, frequentemente, ocupam um terreno em que os extremos se encontram, em que a abjeção do corpo, no prazer ou na dor, é o lugar de uma nova e transformada espécie de identidade e experiência" (Beard, 2006, p. 127, tradução da autora). ${ }^{5}$

Por outro lado, a forma como Cronenberg trata e apresenta o corpo em seus filmes dialoga com uma tendência artística centrada no corpo que vem crescendo, desde a década de 1960, principalmente em sua vertente performática da Body Art, na qual os artistas utilizam o próprio corpo como suporte artístico. Relação que é reconhecida por Cronenberg:

Meus filmes centram-se no corpo. Para mim, o primeiro fato da existência humana é o corpo e quanto mais nos afastamos do corpo humano as coisas se tornam menos reais e precisam ser inventadas por nós. Talvez o corpo seja a única verdade da existência humana a qual possamos nos agarrar. $E$, no entanto, isso parece ser bastante ignorado pelo fazer cinematografico, embora, talvez, não pela arte em geral. Penso em uma porção de singulares e interesantes artistas performáticos e em pintores como Francis Bacon. Mas, no fazer cinematográfico, essa investida a partir do corpo ainda parece ser estranha (Cronenberg, 1999, s.p., tradução da autora). ${ }^{6}$

4 Tradução livre de: "It's not disgust. It's fascination, but it's also a willingness to look at what is really there without flinching, and to say this is what we're made of, as strange and as disgusting as it might seem at times. I'm really saying that the inside of the body must have a completely different aesthetic. I could conceive of a beauty contest for the inside of the human body".

5 Tradução livre de: “Cronenberg's films often occupy a terrain where the extremities meet, where the body's abjection in pleasure or in pain is the site of a new and transformed kind of identity and experience".

6 Tradução livre de:"My films are bodycentric. For me, the first fact of human existence is the body and the further we move away from the human body the less real things become and have to be invented by us. Maybe the body is the only fact of human existence that we can cling to. And yet it seems to be much ignored in movie making, although maybe not in art generally. One thinks of a lot of strange, interesting performance artists and painters like Francis Bacon. But in movie making there still seems to be this flight from the body in a weird way". 
O que na perspectiva de Cronenberg é um contrassenso, uma vez que para ele tudo no processo de filmagem está relacionado ao corpo, que é o cerne da narrativa cinematográfica, tendo como foco primordial o rosto. E a maneira como são filmados os diálogos e os closes depende da forma como o diretor utiliza a linguagem corporal do ator, instaurando diálogos entre a câmera e o corpo através de focos, ângulos e distâncias. Pois, para ele: "qualquer cineasta, se for honesto a respeito disso, percebe que na base do que ele faz está a orientação do corpo e a consciência corporal [...] É tudo linguagem corporal" (Cronenberg, 2007a, s.p., tradução da autora). ${ }^{7}$

\section{A permeabilidade grotesca: o corpo e seus orifícios}

Os orifícios corporais naturais (boca, ânus, vagina) ou criados (por cortes, perfurações e invaginações) são imagens recorrentes no cinema de Cronenberg, espaços de passagem que permitem a invasão do corpo assim como também colocam os elementos interiores (sangue e vísceras) do corpo em contato com o exterior, representando a fronteira entre dentro e fora do corpo. A imagem mais emblemática disso é encontrada em Videodrome, uma enorme e sensual boca feminina apresentada em close, que preenche a tela do televisor como se fosse um órgão independente do resto do corpo. Os órgãos retirados do contexto corporal se revelam transitórios, tornam-se polivalentes, fazendo o que é boca em um nível ser ânus em outro. Ânus e boca, elementos complementares num sistema orgânico "normal", passam a equivaler-se quando a lógica corporal é rompida. Como no episódio do "ânus falante" contado pelo protagonista de Mistérios e paixões: um homem ensina seu ânus a falar, mas perde o controle sobre ele, sendo incapaz de calá-lo, pelo contrário, é sua boca que é emudecida pelo surgimento de uma substância gelatinosa que a obstrui até, finalmente, o cérebro ser dominado e destruído. Para Cronenberg: "O anus falante é uma imagem muito literal do tabu dos orifícios humanos" (Cronenberg citado por Gorostiza, 2003, p. 233, tradução da autora)..$^{8}$ A intenção de provocar o espectador em relação a esse tabu é revelada na penetração das fendas semelhantes à vagina, em Videodrome e em Crash; e dos orifícios semelhantes ao ânus em Enraivecida na fúria do sexo e eXistenZ. E a ambiguidade em relação ao lugar, ânus ou vagina, que está sendo penetrado fica evidente em Crash e em M. Butterfly. Em M. Butterfly é essa imprecisão, René Gallimard penetra o ânus

7 Tradução livre de: "any filmmaker, if he's honest about it, will realize that at the bottom of what he's doing is body orientation and body consciousness [...] It's all body language".

8 Tradução livre de: "El ano parlante es una imagen muy literal del tabú de los orificios humanos". 
acreditando ser a vagina, que o leva a pensar que está tendo relações sexuais com uma mulher.

Além disso, o ânus representa um ponto de indistinção entre a anatomia masculina e a feminina, ponto de ambivalência sexual que fica explícita em existenZ, uma vez que os bioports, orifícios criados no final da espinha dos jogadores para a conexão ao jogo, equiparam os corpos masculino e feminino. Através desse novo orifício, que deve ser penetrado pelo aparato do jogo para que o indivíduo se conecte ao mundo virtual, instaura-se uma nova forma de gozar as possibilidades do corpo. Ao revelar a equidade desses orificios, Cronenberg desconstrói a ordem corporal e a conformidade das partes, pois para ele:

Um orifício é um orifício. Os aspectos sexuais disso são bastante óbvios e a psicologia dos orifícios envolve todos os tipos de sexualidade. Cada orifício passou a ter a sua utilização sexual, incluindo orelhas, narizes e tudo mais. Então, por que esse novo orifício não teria seu aspecto sexual? Claro que tem. Então, para mim, eu só estou revelando coisas que estão lá para serem reveladas (Cronenberg citado por Hattenstone, 2007, s.p., tradução da autora). ${ }^{9}$

A penetração anal e a incerteza em relação ao lugar que está sendo penetrado são frequentes nos filmes do cineasta, que, geralmente, mostram intercursos sexuais nos quais a penetração é realizada por trás, sugerindo o sexo anal. Ato que implica ideias de violência e de dominação, e representa a separação total entre sexo e procriação, reforçando assim a ideia de uma sexualidade cujo objetivo único é o prazer. Tal conduta perturba os valores da moral sexual que, segundo Michel Foucault, apregoa "a pertinência do prazer ao campo perigoso do mal" (Foucault, 1984, p. 218).

\section{O medo da morte me perturba}

Porapresentar recorrentemente um corpo humano que setransforma, que é aberto e invadido, que tem seu interior exposto, esviscerado e sangrentamente dilacerado, e cujos limites são transgredidos, os filmes de Cronenberg, principalmente os primeiros, foram recorrentemente classificados no gênero de horror ou de ficção científica de horror, espaços que convencionalmente

9 Tradução livre de "An orifice is an orifice. The sexual aspects of it are pretty obvious and the psychology of orifices does involve sexuality of every kind. Every orifice has come to have its sexual use, including ears, noses and everything else. So why would this new orifice not have its sexual aspect? Of course it does. So, to me, I'm just revealing things that are there to be revealed". 
comportam essas imagens extremas do chamado body horror. ${ }^{10}$ Esse "horror corporal", ligado à abjeção e ao grotesco, apresenta as mais variadas formas de violação da integridade do corpo, mostrando de todos os ângulos possíveis golfadas de sangue, corpos mutilados, cabeças e ventres explodindo e membros sendo decepados, puxando o espetáculo interno do corpo para o exterior em uma espécie de busca por descobrir qual é o limite do corpo e como transgredilo. Já, para Testa, os repertórios dos filmes de Cronenberg advêm da ficção científica, estando no limiar do gênero de horror por utilizarem o corpo humano como cenário de seu espetáculo.

Para Cronenberg, a origem do gênero de horror está no medo da morte, que resulta no temor ao envelhecimento, à decadência do corpo e à separação das pessoas amadas. A ideia de que o corpo domina e submete o "eu" é algo que inquieta o cineasta:

Por que deveria uma mente saudável morrer, apenas porque o corpo não está saudável? Como pode um homem definhar em uma completa degradação física enquanto a sua mente está absolutamente nítida e clara? (Cronenberg, 2007, p. 79, tradução da autora). ${ }^{11}$

E, para o diretor, foi essa inquietação que o levou a colocar o corpo no centro do espetáculo, e seria esse o aspecto que o aproxima à produção do gênero de horror. Um espetáculo que busca desvelar a fragilidade e a inconstância da natureza do humano, atrelada a um corpo finito, passível de falência e em constante degradação rumo à morte, na qual se revela a natureza de sua condição de animal.

Nesse sentido, coloca em questionamento o binarismo cartesiano no qual a mente, representada pela alma ou pelo espírito, é considerada superior ao corpo. Esse imbricamento entre corpo e mente fica evidente em Filhos do medo, cujo protagonista, Dr. Hal Raglan, busca curar seus pacientes com sessões

10 Esse estilo de filme exacerba o próprio gênero de horror e coloca o corpo humano no centro da narrativa. $O$ que advém da própria gênese do gênero que está na idéia da morte e que conduz ao enfrentamento da consciência da finitude do corpo. Essa reconfiguração do gênero se deu através do trabalho de diretores como George Romero, do agora cult A Noite dos mortos vivos Night of the Living Dead - 1968), Tobe Hooper, do recentemente refilmado Massacre da serra elétrica (Texas Chain Saw Massacre - 1974); John Carpenter, de Halloween (1978), obra com inúmeras continuações; Wes Craven, do também recentemente refilmado Quadrilha de sádicos (The Hills Have Eyes - 1978); e o italiano Dario Argento, de Prelúdio para matar (Profondo Rosso - 1976) e Suspiria (1977). Todos esses diretores e, de forma emblemática nesses filmes apontados, trazem o terror para os espectadores através da possibilidade de destruição do corpo, que não significa a sua simples eliminação, mas sim a exposição mais sangrenta possível de sua agonia.

11 Tradução livre de: "Why should a healthy mind die, just because the body is not healthy? How can a man die a complete physical wreck, when his mind is absolutely sharp and clear?" 
de psicodrama, que os induz a psicoplasmarem seus piores sentimentos. Uma espécie de transformação da percepção freudiana em relação ao estatuto do corpo na psicanálise, de que o quê a histérica mostra é algo de si, em seu corpo, pela via do sintoma, que faz o diálogo entre corpo e psique.Pois o corpo somático e o psiquismo se encontram através da pulsão, que é “o representante psíquico dos estímulos oriundos do interior do corpo que alcançam a psique, como uma medida da exigência de trabalho que é imposta ao psíquico em decorrência de sua conexão com o corpóreo" (Freud, 1996, p. 85). No filme, Nola, enraivecida e descontrolada, evoca o imaginário da mulher histérica estudada por Freud, mas em seu caso a manifestação física do mal psíquico é uma tentativa de purgá-lo e não seu sintoma. A terapia utilizada por Raglan inverte a lógica freudiana, ao invés de partir do sintoma físico para desvelar a condição psíquica, parte dos traumas psicológicos para desencadear as manifestações físicas.

Filhos do medo pode ser visto, então, como uma metáfora do cinema cronenberguiano, uma vez que em seus filmes os estados de ânimo dos personagens acabam sempre se refletindo em seus corpos. A ideia da indissociação entre corpo e mente, fica evidente em Scanners e Spider, nos quais os processos mentais (sentimentos de medo, fúria, desejos, telepatia, etc.) têm repercussão direta sobre o corpo. Em Scanners, ao utilizar seus poderes telepáticos, o scanner, Cameron, sofre sintomas físicos: seu nariz sangra e ele sente fortes dores de cabeça, náuseas e cólicas estomacais. Além disso, seu poder age sobre o corpo do outro, ao qual domina e destrói, como na famosa cena em que um scanner faz explodir a cabeça de outra pessoa. E quando Cameron tem seu corpo destruído, sua mente invade o corpo do irmão, pois não pode existir desencarnada. Já em Spider, o protagonista esquizofrênico, que dá nome ao filme, rechaça o mundo exterior, vivendo em um mundo de memória e fantasia, que interfere em sua percepção da realidade e se reflete sobre seu corpo, encurvado e de movimentos curtos e tensos como se buscasse fechar-se sobre si mesmo.

\section{O devir-corpo dos personagens cronenberguiano}

O constante processo de transformação dos corpos dos personagens de Cronenberg resulta em um processo constante de transformação de suas identidades, uma vez que as duas instâncias estão imbricadas. Os protagonistas cronenberguianos não têm corpo, eles são o corpo. E a consciência dessa metamorfose ininterrupta está no cerne de seus conflitos, que, quase sempre, têm a morte como único fim possível, sendo sua condição uma metáfora da própria vida. 
O corpo cronenberguiano pode ser reconhecido, então, um devir-corpo, no sentido de devir proposto por Gilles Deleuze:

\begin{abstract}
Devir é nunca imitar, nem fazer como, nem se conformar a um modelo, seja de justiça ou de verdade. Não há um termo do qual se parta, nem um ao qual se chegue ou ao qual se deva chegar. Tampouco dois termos intercambiantes. A pergunta 'o que você devém?' é particularmente estúpida. Pois à medida que alguém se transforma, aquilo em que ele se transforma muda tanto quanto ele próprio. Os devires não são fenômenos de imitação, nem de assimilação, mas de dupla captura, de evolução não paralela, de núpcias entre dois reinos (Deleuze, 1998, p. 184).
\end{abstract}

O devir-corpo cronenberguiano não busca atingir uma forma, mas é, sim, um eterno processo de transformação, que busca "encontrar a zona de vizinhança, de indiscernibilidade ou de indiferenciação tal que não seja possível distinguir-se de uma mulher, de um animal, de uma molécula: não imprecisos nem gerais, mas imprevistos" (Deleuze, 1997, p. 11).

Nesse sentido, Videodrome seria um manifesto cronenberguiano do devircorpo, no qual a ideia da "nova carne", transformação do corpo real em um corpo virtual, passando pelo imbricamento entre corpo e tecnologia, representa o potencial de transformação e adaptação do corpo. Para Cronenberg:

A perspectiva mais acessível da 'Nova carne' em Videodrome seria que você realmente pode mudar o que significa ser um ser humano em um sentido físico. Nós certamente mudamos no sentido psicológico desde o início da humanidade. Na verdade, nós mudamos fisicamente também. Estamos fisicamente diferentes de nossos antepassados, em parte, em decorrência da maneira como usamos nossos corpos e, em parte, por causa de coisas como óculos e cirurgias. Mas há mais um passo que poderia acontecer, que poderia ser você fazer crescer um outro braço, que você, efetivamente, pudesse mudar fisicamente a sua aparência - mutação (Cronenberg, 1997, p. 80-81, tradução da autora). ${ }^{12}$

Desde suas apresentações extremas do devir-corpo nos filmes Calafrios, Enraivecida na fúria do sexo, Filhos do medo, Videodrome e $A$ mosca, até as mais

12 Tradução livre de: "The most accessible version of the 'New Flesh' in Videodrome would be that you can actually change what it means to be a human being in a physical way. We've certainly changed in a psychological way since the beginning of mankind. In fact, we have changed in a physical way as well. We are physically different from our forefathers, partly because of what we take into our bodies, and partly because of things like glasses and surgery. But there is a further step that could happen, which would be that you could grow another arm, that you could actually physically change the way you look - mutate". 
manifestações mais realistas em Marcas da violência, Senhores do crime, Um método perigoso, Cosmópolis e Mapas para as estrelas, o corpo é a essência da existência dos personagens cronenberguianos, que através dele buscam se reconhecer, confrontando sua inconstância e a incerteza de suas identidades.

Uma das mais eloquentes formas de configuração do devir-corpo cronenberguiano é a figura do corpo-híbrido, no qual a hibridez não é o resultado final de um entrecruzamento, mas sim, um constante vir a ser. Nesse aspecto, os filmes de Cronenberg reafirmam uma tradição das artes americanas na qual a metamorfose, que origina o híbrido, é a forma mais adequada de definir a constante transformação na formação cultural do continente. Uma vez que, como salienta Bernd, o monstruoso, configurado pelo híbrido, representa o exílio desses seres "no interior de si próprios e de seu país, em razão de uma natureza que os afasta dos demais" (Bernd, 1998, p. 261). O híbrido representa, então, identidades em devir, identidades em constante transformação: construídas, ambíguas, heterogêneas e deslocadas, que resultam da justaposição e interação de diferentes culturas.

Esse processo ocorre em M. Butterfly, no qual as culturas oriental e ocidental se hibridam, tendo o corpo humano como território de conflito e de comunhão. O corpo misterioso de Song Liling, encoberto pela fantasia da mulher oriental, acaba por ser desvelado a Gallimard, revelando, em sua nudez masculina, a incerteza desse corpo. Em sentido inverso a essa metamorfose da borboleta/mulher em homem, ocorre à transformação de Gallimard em uma versão grotesca de Madame Butterfly. Vestindo um quimono improvisado e com unhas pintadas de vermelho, ele maquia-se burlescamente, olhandose em um pedaço de espelho. Nas duas perspectivas, no travestimento e no desvelamento, há uma tentativa de assimilação da outra identidade e de outra cultura através do próprio corpo, que, no entanto, culmina com o espetáculo sangrento do autossacrifício de Gallimard. Assim como Seth, em A mosca, Gallimard se transforma em um monstro ao fusionar-se com o outro, pois suas metamorfoses são incapazes de conciliar os elementos distintos que compõem suas identidades transitórias, que resultam em um hibrido estéril e sem futuro.

\section{O devir-animal dos personagens cronenberguiano}

Em A mosca, o devir-corpo avança à condição de devir-animal na transformação de Seth Brundle. O descuido em um experimento misturou a genética de Brundle à de uma mosca, gerando um ser único, diferente de ambos, cuja transformação só cessa com sua morte. Seu corpo passa a ser uma zona de indiscernibilidade, que tende a escapar, dissipando-se, sendo "apenas uma 
etapa para um devir imperceptível mais profundo no qual a Figura desaparece" (Deleuze, 2007, p. 35). Deleuze e Guatttari explicam:

O devir não produz outra coisa senão ele próprio. [...] O que é real é o próprio devir, o bloco de devir, e não os termos supostamente fixos pelos quais passaria aquele que se torna. $O$ devir pode e deve ser qualificado como devir-animal sem ter um termo que seria o animal que se tornou (Deleuze; Guattari, 2004, p. 18).

A metamorfose de Brundle, seu devir-animal, rompe os limites entre o humano e o animal (inseto), tornando impossível diferenciar um do outro. Nesse devir, seu corpo se dissipa e escapa abandonando pedaços (orelhas, unhas e dentes) que se desprendem viscosos e que são expelidos em golfadas de um vomito espesso e corrosivo.

O devir-animal dos personagens cronenberguianos, também, se revela nas cenas extremas de violência e de sexo que expõem a natureza mais atávica desses corpos, uma essência animal que só se manifesta no processo de contato com outro corpo. O corpo é apresentado então como entidade primeira da existência humana, havendo uma relação inerente entre corpo e violência:

Meu entendimento de violência é de que é tudo corpo, é tudo físico. Quando falamos de violência, não estamos falando sobre a explosão de um edifício, nós estamos falando sobre corpos sendo destruído. E eu levo isso muito a sério, porque, você sabe, eu sou um ateu, e eu acredito que o seu corpo é você. Esse é o primeiro fato da existência humana, e, realmente, a única verdade. Então, se você matar alguém, para mim esse é um ato absoluto de destruição (Cronenberg, 2007b, s.p., tradução da autora). ${ }^{13}$

Ao ancorar Marcas da violência e Senhores do crime em episódios pujantes de violência, Cronenberg explicita essa relação entre corpo e violência. Em Senhores do crime, há uma impressionante cena de luta, na qual Nikolai, nu em uma casa de banho, é atacado por gangsteres armados com facas. Seu corpo recoberto por tatuagens, másculo e ágil, é macerado por golpes e facadas, e sua nudez expõe a fragilidade de seu corpo. Por outro lado, a luta com facas exige o contato físico, criando um balé de movimentos de ataque e de defesa

13 Tradução livre de: "My understanding of violence is that it's all body, it's all physical. When we talk about violence, we're not talking really about a building blowing up, we're talking about bodies being destroyed. And I take that very seriously because, you know, I'm an atheist, and I think your body is you. That's the first fact of human existence, and, really, the only fact. So if you kill somebody, to me that's an absolute act of destruction". 
que revela a natureza do corpo, que se fundamenta na possibilidade de contato com outro corpo, no corpo a corpo. Acerca dessa relação entre os corpos, falam Deleuze e Guattari:

Não sabemos nada de um corpo enquanto não sabemos o que pode ele, isto é, quais são seus afectos, como eles podem ou não comporse com outros afectos, com os afectos de um outro corpo, seja para destruí-lo ou ser destruído por ele, seja para trocar com esse outro corpo ações e paixões, seja para compor com ele um corpo mais potente (Deleuze; Guattari, 2004, p. 43).

A violência e o sexo são, então, duas potencialidades latentes do corpo ao contato com outro corpo e não necessariamente opostas. Perspectiva que conflui com a visão de Cronenberg de que: "Sexo e violência sempre se deram muito bem juntos, como bacon e ovos. Se olharmos para a história da violência cinematográfica, há sempre um componente sexual na violência e um componente violento na sexualidade" (Cronenberg, 2008, s.p., tradução da autora $)^{14}$.

As cenas de violência e de sexo, que levam os corpos ao extremo, revelam a natureza animal desses corpos entregues a seus instintos mais primitivos. Nessas cenas, os personagens cronenberguianos são apresentados em seu devir-animal, em um deslizar constante entre as duas instâncias, no qual o limite entre os corpos é borrado em sua interação. A disformidade ou a criação de novas formas geradas na imagem da conjunção desses corpos revela a real natureza do corpo: instável, movediça e passageira.

Marcas da violência apresenta duas intensas cenas de sexo que geraram controvérsia. Na primeira, o casal de protagonistas inicia uma brincadeira sexual, fantasiando o sexo adolescente, a esposa está vestindo um uniforme de animadora de torcida, que culmina com um ato de sexo oral recíproco. Já a segunda cena inicia com uma discussão do casal, a mulher esbofeteia o marido que parte para ela com violência, dominando-a sobre as escadas, mas arrependido ele tenta soltá-la, sendo, então, segurado por ela, e eles se entregam a um momento de sexo violento.

A forte presença do sexo e a busca por novas possibilidades sexuais estão quase sempre envolvidas nas questões que regem o comportamento dos personagens cronenberguianos. E a forma como Cronenberg apresenta a sexualidade e as questões a ela envolvidas transgride padrões estéticos, morais

14 Tradução livre de: "Sex and violence have always got on very well together, like bacon and eggs. If you look at the history of cinematic violence, there is always a sexual component in violence and a violent component in sexuality". 
e sociais, confrontando tabus com imagens ousadas e extremas e imaginando novas possibilidades para a sexualidade, que vão além dos limites corporais centrados nos órgãos sexuais e na reprodução: "Somos livres para desenvolver diferentes tipos de órgãos que dão prazer, eque não tenham nada a ver com sexo" (Cronenberg, 1997, p. 82, tradução minha). ${ }^{15}$ As novas possibilidades sexuais e corporais vislumbradas por Cronenberg põem em discussão o potencial de transformação do corpo, através da ciência e da tecnologia, estando à relação entre os seres humanos e a sexualidade atrelada a essas transformações, apresentando, assim, uma sexualidade em devir.

\section{O devir-monstro dos personagens femininos de Cronenberg}

Creed utiliza o conceito de abjeção, proposto por Julia Kristeva, para analisar a representação da mulher e do corpo feminino no cinema de horror. Para Creed, o temor ao corpo feminino está na gênese do gênero de horror, literal ou simbolicamente e, também, na origem das implicações sexuais recorrentes nesse gênero. ${ }^{16}$ Além disso, o fato de serem os órgãos sexuais femininos internos, e não expostos como os masculinos, intensifica a curiosidade acerca deste universo biológico escondido nas entranhas, que encerram os mistérios da reprodução:

O útero representa o máximo em abjeção, pois contém uma nova forma de vida que vai passar de dentro para fora, trazendo consigo traços dessa contaminação - sangue, placenta, fezes. [...] O filme de terror explora a natureza abjeta do útero, representando o humano, feminino e masculino, dando a luz ao monstruoso (Creed, 1994, p. 49, tradução da autora) $)^{17}$.

O corpo dos personagens femininos de Cronenberg é construído a partir da abordagem de seus mistérios, sendo simultaneamente sedutor e assustador, configuração evidente em Enraivecida na fúria do sexo que apresenta uma mulher mutante predadora, misto de zumbi e vampira. A gravidez e suas representações simbólicas estão presentes em Filhos do medo, Scanners,

15 Tradução livre de: "We're free to develop different kinds of organs that would give pleasure, and that have nothing to do with sex".

16 Exemplos emblemáticos de como o gênero de horror articula os temores referentes ao corpo feminino e a seus mistérios relacionados à sexualidade e à procriação são apresentados nos filmes: O bebê de Rosemary (Rosemary's Baby - 1968), de Roman Polanski; O exorcista (The Exorcist - 1973), de William Friedkin; Carrie, a estranha (Carrie - 1976), de Brian de Palma.

17 Tradução livre de: "The womb represents the utmost in abjection for it contains a new life form which will pass from inside to outside bringing with it traces of its contamination - blood, afterbirth, faeces. [...] The horror film exploits the abject nature of the womb by depicting the human, female and male, giving birth to the monstrous". 
Videodrome, A mosca, Gêmeos: mórbida semelhança, M. Butterfly e Senhores do crime. Conforme Bear, uma das posições ocupadas pelos personagens femininos do Cronenberg é justamente a de "horrivelmente maternal, 'feminino monstruoso', corpo feminino abjeto" (Beard, 2006, p. 224, tradução da autora). ${ }^{18}$ Como se vê em Filhos do medo e Gêmeos; no primeiro, Nola transforma-se em uma mãe monstruosa, gerando, através da corporificação de sua raiva, em sacos placentários extracorpóreos criaturas assassinas, que pare de maneira animalesca. E, no segundo, Claire Niveau procura a clínica dos gêmeos Mantle em busca da cura para sua infertilidade, que descobre ser resultado de um útero aberrantemente trifurcado. Em Scanners, a gestação é interferida pelo Efemerol, uma medicação que causa a mutação dos fetos, transformando-os em scanners, seres com extraordinários poderes telepatas. Já em $A$ mosca, ao descobrir que está grávida do já mutante Brundlefly, Veronica sonha que está dando à luz uma larva gigante. Em M. Butterfly, o desconhecimento do corpo feminino chega ao extremo, Gallimard mantém relações sexuais com outro homem, acreditando tratar-se de uma mulher. $\mathrm{O}$ jogo de sedução e mistério altera a cartografia do corpo feminino a partir da fantasia masculina em relação ao território estrangeiro que o corpo feminino representa. E em Crash, o corpo feminino é um local misterioso de experimentação e exploração, seja o corpo perfeito de Catherine ou corpo reconstruído pela tecnologia das próteses de Gabrielle, cuja cicatriz similar a uma vagina em sua perna é vista por Ballard como um novo órgão sexual.

A estranheza do feminino se caracteriza então pela abjeção gerada por seu corpo que deriva de sua natureza animal e sexual, que é exposta pelo processo de reprodução cujas transgressões e desvios minam a ordem social. $O$ corpo feminino é ameaçador por representar ao mesmo tempo a sexualidade tentadora e a repulsa física, assim como por fazer lembrar tanto do nascimento quanto da morte. Os filmes de Cronenberg destacam essa essência assustadora, revelada no devir-monstro do corpo feminino, que permeia o imaginário humano: "Todas as sociedades têm uma concepção do feminino-monstruoso, e do que na mulher é chocante, terrível, horrível, abjeto" (Creed, 1994, p. 1, tradução da autora). ${ }^{19}$ Mas esse potencial assustador de geração do corpo feminino, no qual reside sua monstruosidade, é também a origem de sua força e pode ser visto como uma potência criativa. O devir-monstro dos personagens femininos está, então, em consonância ao devir-animal, uma vez que é norteado pela condição

18 Tradução livre de: "horrifically maternal,'monstrous feminine', abject female body".

19 Tradução livre de: "All human societies have a conception of the monstrous-feminine, of what it is about woman that is shocking, terrifying, horrific, abject". 
mais visceral da natureza do feminino, sua capacidade de reprodução. Ao dar visibilidade a essa força animal, Cronenberg subverte a antiga representação do corpo feminino que deixa de ser um corpo submisso para tornar-se um corpo efervescente, transformador e criativo, que anuncia uma outra identidade, muitas vezes, assustadora.

\section{O devir-máquina cronenberguiano}

Obras emblemáticas na cinematografia de Cronenberg, Videodrome e eXistenZ são notoriamente conhecidos por apresentam o imbricamento entre o corpo dos personagens e a tecnologia investigada em cada um dos filmes: a televisão, no primeiro, e o vídeo-game, no segundo. A tecnologia é apresentada, então, enquanto manifestação da inteligência criadora humana sendo, também, parte de sua natureza e, por isso, está diretamente ligada ao corpo como possibilidade de expansão e de melhoria de suas potencialidades.

Esse devir-máquina do corpo está, então, entre a organicização da máquina e a tecnologização do corpo, criando híbridos homem-tecnologia que extrapolam as noções de ciborgues protéticos e interpretativos, configurandose como possibilidades do pós-humano, pois questionam a adequação do corpo humano às atuais necessidades do indivíduo. Esse imbricamento corpotecnologia se dá também de forma mais realista em Crash, sendo construído pelos acidentes automobilísticos em decorrência dos quais é preciso reconstruir o corpo e a identidade. O corpo é resignificado pelas feridas, pela mutilação, pelas cicatrizes, pelas próteses e aparelhos ortopédicos, transformando-se em um novo corpo que não é desagradável aos personagens, pelo contrário, é cultuado, mudando também a percepção dos personagens a respeito do próprio corpo. E a recartografia do corpo através desses processos reforça a diferença dessa representação em relação ao cânone corporal clássico.

\section{Devir-corpo... O corpo por vir}

Mesmo que exista uma notória diferença entre a estética de seus primeiros filmes, que tangenciam a estética do gênero de horror, e sua produção mais recente, filmes mais realistas, a obra de Cronenberg segue norteada pelo corpo. Através do qual, investiga a condição humana, sendo a voz de uma época em que as múltiplas possibilidades científicas colocam em discussão os limites do corpo e da vida, bem como os limites sociais, culturais e naturais. E revela, assim, a fragilidade das certezas sobre as quais o indivíduo tentou por muito tempo se afirmar, levando ao repensar da condição do próprio corpo e, por conseguinte, ao repensar da própria condição do humano. 
Conforme Le Breton (2003), o corpo é atualmente uma identidade provisória, um lugar de encenação, ou seja, não é mais a encarnação irredutível ou a fatalidade ontológica que sustentava os processos identitários modernos, mas uma construção pessoal, disponível para múltiplas metamorfoses e performances, um objeto transitório e manipulável. Cada vez mais o indivíduo se torna bricoleur de seu corpo graças às infinitas possibilidades de transformá-lo e de aprimorá-lo seja em relação à mudança de sua aparência, à potencialização de suas funções, ou ao prolongamento de sua existência.

Esses processos, atualmente, cotidianos de reconfiguração do corpo e de suas funções, têm sido objeto de importantes discussões acerca da bioética e do biopoder. Questões que vêm sendo tratadas por Cronenberg desde seus primeiros trabalhos como, por exemplo: Calafrios, Enraivecida nas fúrias do sexo, Scanners, Videodrome e A mosca; nos quais intervenções científicas e, também, políticas agem sobre o corpo coletivo e individual; até os seus mais recentes filmes como: Marcas da violência, que aborda o tráfico de pessoas.

$\mathrm{O}$ incomodo gerado pelos filmes de Cronenberg advém da maneira explícita como expõem esse devir-corpo, um corpo em constante transformação que tende, por um lado, ao devir-máquina e, por outro, ao devir-animal e devirmonstro, estando sempre atrelado ao grotesco e à abjeção que sinalizam o final inquestionável desse corpo e de todos os outros; a morte. O realmente perturbador talvez esteja no fato de o espectador reconhecer-se na mesma condição dos personagens cronenberguianos, em constante embate contra a natureza finita do próprio corpo e contra o processo de degradação que não cessa, tendo como única certeza o fato de que não há como escapar da morte pelo menos até agora.

Por outro lado, a obra de Cronenberg sugere que os constantes avanços da tecnologia e da ciência prometem caminhos nunca antes imaginados para a reconfiguração do corpo, cujo objetivo não é apenas estender ou ampliar as capacidades do corpo, mas, também, ultrapassar as limitações inerentes à própria condição finita do humano, sendo essa perspectiva incerta do corpo por vir, o que, realmente, angustia.

\section{REFERÊNCIAS}

BAKHTIN, Mikhail. A cultura popular na Idade Média e no Renascimento: o contexto de François Rabelais. São Paulo: Hucitec; Brasília: Editora da Universidade de Brasília, 1999.

BEARD, William. The Artist as Monster: The Cinema of David Cronenberg (Revised 
and Expanded) Toronto: University of Toronto Press, 2006.

BERND,Zilá. Escrituras híbridas:estudos em literatura comparada e interamericana. Porto Alegre: Editora da Universidade/UFRGS, 1998.

CRONENBERG, David. Cronenberg on Cronenberg. 2 e. London: Faber and Faber, 1997. Entrevista concedida a Chris Rodley.

.The Film Director as Philosopher: An Interview with David Cronenberg. Cineaste, v. 24, n. 4, outono, 1999. Entrevista concedida a R. Porton.

Íntegra da entrevista com o diretor americano David Cronenberg. Revista Época, nov. 2005. Entrevista concedida a Marcelo Bernardes. Disponível em: $<$ http://revistaepoca.globo.com/Revista/Epoca/0 „EDG72159-5856,00.html>. Acesso em: 20 mar. 2015.

David Cronenberg: Interviews with Serge Grünberg. London: Plexus, 2006. Entrevista concedida a Serge Grunberg.

Body Language: An Interview With David Cronenberg. Underwire, 29 dez. 2007a. Entrevista concedida a Lewis Wallace. Disponível em: <http://www. wired.com/2007/12/body-language-a/>. Acesso em: 25 jan. 2015.

Eastern Promises'Q\&A:David Cronenberg. Premiere.com. set. 2007b. Entrevista concedida a Matt Mueller.Disponível em:<http://www.mattmueller.co.uk/index. php?page id=Interviews\%20/\%20Features\&category id=Online\&article $\mathrm{id}=146$ > . Acesso em: 12 fev. 2015.

Sex on Film: David Cronenberg - The director of 'A History of Violence' on why sex and violence go together like a horse and carriage. Telegraph, abr. 2008. Entrevista concedida a Karl Rozemeyer Disponível em: <http://www.telegraph. co.uk/culture/film/3646749/Sex-and-violence-go-well-together.html>. Acesso em: 25 mai. 2015.

CREED, Barabara. The Monstrous-Feminine: Film, Feminism, Psychoanalysis. (Popular Fiction Series). London: Routledge, 1994.

DELEUZE, Gilles. Francis Bacon: lógica da sensação. Rio de Janeiro: Jorge Zahar, 2007. ;PARNET, Claire. Diálogos. São Paulo: Escuta, 1998.

Crítica e clínica. Rio de Janeiro, Editora 34, 1997.

; GUATTARI, Felix. Mil platôs: capitalismo e esquizofrenia. v. 4. São Paulo: Editora 34, 2004.

FOUCAULT, Michel. História da sexualidade 2: o uso dos prazeres. Rio de Janeiro: Graal, 1984. 
FREUD, Sigmund. Luto e melancolia (1914-1916). A história do movimento psicanalítico, v. XIX. Rio de Janeiro: Imago, 1996.

GOROSTIZA, Jorge; PÉREZ, Ana. David Cronenberg. (Signo e Imagem/Cineastas). Madrid: Cátedra, 2003.

HATTENSTONE, Simon. Gentleman's relish. The Guardian, 6 out. 2006. Disponível em: $\quad<$ http://www.guardian.co.uk/film/2007/oct/06/londonfilmfestival2007. londonfilmfestival>. Acesso em: 27 abr. 2007.

KRISTEVA, Julia. Pouvoirs de 1'horreur. Paris: Éditions du Seuil, 1980.

LE BRETON, David. Adeus ao corpo. Antropologia e Sociedade. Campinas: Papirus, 2003.

SHAVIRO, Steven. Bodies of Fear: David Cronenberg. In: The Cinematic Body. Minneapolis: University of Minnesota Press, 1993. Disponível em: <http://www.bluesunshine.com/tl files/images/Week5-Shaviro-BodiesFear.pdf>. Acesso em: 18 abr. 2015.

SMITH, Murray. (A) moral monstrosity. In: GRANT, Michael. The Modern Fantastic: The Films of David Cronenberg. Canadá: Praeger Published, 2000.

TESTA, Bart. Panic Pornography: Videodrome from Production to Seduction. In: Canadian Journal of Political and Social Theory, v. 13, 1989, p. 56-72.

\section{Filmografia}

A mosca. Direção: David Cronenberg. Canadá, Estados Unidos: Brooksfilme, 1986. DVD (96 min), son., color., legendado. Tradução de: The Fly.

Calafrios. Direção: David Cronenberg. Canadá: Cinépix, 1975. DVD (87 min), son., cor., legendado. Tradução de: Shivers.

Crash: estranhos prazeres. Direção: David Cronenberg. Canadá, Inglaterra: Alliance Communications Corporation, 1996. DVD (100 min), son., cor., legendado. Tradução de: Crash.

Enraivecida na fúria do sexo. Direção: David Cronenberg. Canadá: Cinépix, 1976. DVD (91 min), son., cor., legendado. Tradução de: Rabid.

eXistenZ. Direção: David Cronenberg. Canadá, Inglaterra: Alliance Communications Corporation, 1999. DVD (97 min), son., cor., legendado.

Filhos do Medo. Direção: David Cronenberg. Canadá: Victor Solnicki Productions, 1979. DVD (92 min), son., cor., legendado. Tradução de: The Brood 
Gêmeos: mórbida semelhança. Direção: David Cronenberg. Canadá:Téléfilm Canada, 1988. DVD (116 min), son., cor., legendado. Tradução de: Dead Ringers.

Marcas da Violência. Direção: David Cronenberg. Canadá, Estados Unidos: New Line Cinema, 2005. DVD (96 min), son., cor., legendado. Tradução de: A History of Violence.

M. Butterfly. Direção: David Cronenberg. Canadá, Estados Unidos: Geffen Pictures, 1993. DVD (101 min), son., cor., legendado.

Mistérios e Paixões. Direção: David Cronenberg. Canadá, Inglaterra: Film Trustees Ltd., 1991. DVD (115 min), son., cor., legendado. Tradução de: Naked Lunch.

Scanners: sua mente pode destruir. Direção: David Cronenberg. Canadá: Filplam, 1980. DVD (103min), son., cor., legendado. Tradução de: Scanners.

Senhores do crime. Direção: David Cronenberg. Canadá, Inglaterra: Focus Feature, 2007. DVD (100 min), son., cor., legendado. Tradução de: Eastern Promises.

Spider: desafie sua mente. Direção: David Cronenberg. Canadá, Inglaterra: Odeon Films, 2002. DVD (98 min), son., cor., legendado. Tradução de: Spider.

Videodrome: síndrome do vídeo. Direção: David Cronenberg. Canadá: Famous Players, 1983. DVD (87 min), son., cor., legendado. Tradução de: Videodrome.

Recebido em: 30/07/2015

Aceito em: 18/09/2015

Endereço da Autora:

Rosângela Fachel de Medeiros < rosangelafachel@gmail.com $>$

Av. Assis Brasil, 709 - Bairro Itapagé

CEP 98400-000

Frederico Westphalen, RS - Brasil 